\title{
Increasing 2-yr Student Graduation and Transfer Rates through STEM In- dustrial and Academic Partnerships
}

\section{Dr. Pamela M Leggett-Robinson, Georgia Perimeter College}

Dr. PAMELA LEGGETT-ROBINSON is the Science Department Chair and an Associate Professor of Chemistry on the Decatur campus of Georgia Perimeter College. She earned her B.S. in Chemistry from Georgia State University and M.S. in Bio-Inorganic Chemistry from Tennessee Technological University. She received her Ph.D. in Physical Organic Chemistry from Georgia State University in 2003. Dr. Leggett-Robinson is the Principal Investigator of GPC's \$1.5 million NSF STEP grant and continues to work closely with as other STEM committees as well as on graduation/transfer committees. Dr. LeggettRobinson is published in the Journal of College Science Teachers, Polymer, the Journal of Undergraduate Chemical Research, Heterocyclic Communications, the Journal of Oncology and Hematology, and The Chemical Educator. She has made numerous presentations at both national and regional scientific meetings and has been featured in in a TRIO publication (Council of Education) highlighting "Academic AllStars", in the ACS publication In Chemistry, in a Science Education publication from Cornell University, and twice in Georgia Perimeter College's publication The Chronicle.

Mrs. Naranja C. Davis, Georgia State University

Dr. Brandi Campbell Villa, Belay Consulting 


\section{Increasing 2-yr Student Graduation and Transfer Rates through STEM Industrial and Academic Partnerships}

\section{Background}

The most recent data from the National Center for Education Statistics (NCES) reports that more than 40 percent of all first year college students in the United States attend a public or private community college. However, graduation and transfer rates for students attending 2-year institutions and pursuing 4-year degrees are disappointingly low, especially those students majoring in science, technology, engineering, and mathematics (STEM) disciplines. According to the Hechinger Report ${ }^{1}$ and the National Center for Education Statistics ${ }^{2}$ fewer than one out of five students (13\%) at community colleges obtain their desired degree in two years. Within three years, approximately 22 percent of students graduate, and within four years, the rate stands at 28 percent. Thus, developing and implementing successful practices for increasing graduation and transfer rates have been and continue to be problematic for academic leaders concerned with promoting the pathway to the baccalaureate degree for 2-year college STEM students.

Research conducted by Olson et $\mathrm{al}^{3}$ indicates that student persistence towards a STEM degree is associated primarily with intellectual engagement and achievement. Students who play an active role in the pursuit of scientific knowledge learn more and develop more confidence in their abilities, thereby increasing their persistence in STEM majors. This engagement can be accomplished in the classroom as well as outside the classroom. Many types of "outside" classroom instruction (i.e., research opportunities and industrial partnerships) actively engage students, build critical thinking skills, increase problem solving, induce more positive attitudes toward STEM, and increase retention of students in STEM majors. "Outside” classroom instruction such as undergraduate research programs, summer bridge research programs, and partnerships between 2-year and 4-year institutions are essential mechanisms to facilitate increased graduation and transfer rates of students at 2-year institutions to 4 -year institutions. ${ }^{4,5}$ These programs provide exposure to meaningful applications of basic scientific principles and reinforce knowledge presented in the classroom.

This paper describes a Science, Technology, Engineering, and Mathematics Talent Expansion Program (STEP) program at a2-year college whereby “outside” classroom instruction via STEM industry visits and undergraduate research opportunities were provided to program participants in an effort to increase graduation and transfer rates. During STEM industry visits, program participants interacted with STEM professionals, toured STEM industrial research laboratories, learned about cutting-edge technology, and gained information regarding skills that are highly sought by STEM employers. The 3+8 STEM undergraduate research program successfully engaged students from various backgrounds and family/work obligations in scholarly research with university faculty. We report that exposure to real world work environments, via "outside classrooms" (STEM industrial and academic partnerships) improves graduation and transfer rates of participating 2-year college students. 


\section{Institution}

This STEP program involves a two-year public college in the state of Georgia. This institution provides a convenient and affordable non-residential, two-year program with five campuses and one online division. This is the third largest institution in the system and the largest associate degree-granting institution in the state of Georgia. The Fall 2011 full-time enrollment (FTE) for both STEM and Non-STEM students was 20,466. Due to the non-traditional status of many of the students, an equation is employed to calculate full-time equivalents when defining FTE. Table 1 shows enrollment and graduation rates for STEM and non-STEM students. STEM students are defined as those that have enrolled in or taken Pre-Calculus and/or Principles of Chemistry.

Table 1. Institutional enrollment, graduation, and transfer rates for STEM and non-STEM students entering 2011-2012.

\begin{tabular}{llll}
\hline & STEM Students & Non-STEM Students & Total \\
\hline Enrollment (FTE) & 4402 & 18702 & 20466 \\
$\begin{array}{l}\text { Graduates 2013-2014 } \\
\text { (Associates degree) }\end{array}$ & $154(3 \%)$ & $1533(8 \%)$ & $1,687(8 \%)$ \\
$\begin{array}{l}\text { Transfers 2013-2014 } \\
\text { (to 4-year institution) }\end{array}$ & $542(12 \%)$ & $5302(28 \%)$ & $5844(29 \%)$ \\
\hline
\end{tabular}

\section{Program Information}

Beginning in Spring 2012, through National Science Foundation funding, a STEP program was developed for 2-year, full-time students, with a minimum 2.8 grade point average. To participate, students must have U.S. citizenship or status as permanent resident alien or refugee alien and be majoring in a STEM field of study. The objectives of the program are two-fold: 1) to increase the number of students (U.S. citizens or permanent residents) who enroll in all STEM fields (chemistry, biology, math, geology, physics, computer science, and engineering) and 2) to increase the number of students who graduate and/or transfer to four-year colleges/universities to complete their STEM baccalaureate degrees. STEP (at this 2-year institution) does this through a number of student support mechanisms for accepted STEM students:

-Implementing SI in many first year courses (math and chemistry in particular)

-Summer Bridge Research Opportunities (3 week, 8 week, and Research Experiences for Undergraduates (REU) options)

-Civic Engagement (students are required to complete 10 hours per semester)

-Industry Visits (day-long trips to local STEM-relevant companies)

-University Visits (tours of campuses and research labs at 4-year institutions)

-Student Stipends (variable and determined by participation in program elements) 
In an effort to increase degree attainment and transfer in STEM fields, STEM industrial and academic partnerships were developed to allow for student visits and research opportunities. Through partnering with external institutions, students are exposed to possible academic and career pathways, including research fields, institutions to which they could transfer to obtain their 4-year degrees, and potential employers.

Students participate in the program for an average of 3 semesters (including a summer semester). Stipends are given to those participants that meet the following criteria each semester: (1) be enrolled as a full-time student (12 credit hours during the fall and spring semester); (2) maintain a cumulative minimum GPA of 2.8 and a minimum semester GPA of 2.5; (3) participate in a minimum of 10 hours of STEM civic engagement activities per semester; (4) participate in a minimum of six STEM-related activities (STEP-sponsored and others). Stipend amounts vary depending on the classification of the participant. Additional stipends are given for participation in Summer Bridge I undergraduate research experience (3 weeks), Summer Bridge II undergraduate research experience (8 weeks), and REU participation. STEP sponsors multiple STEM activities each semester, including STEM industry visits and college visits.

\section{$\underline{\text { STEM Industrial Partnerships }}$}

Connecting corporations to the educational pipeline is critical to ensuring that the United States has a competitive workforce in STEM fields. Increased collaboration between community colleges and employers holds the promise of reducing skill mismatches in the marketplace. ${ }^{6}$ Many STEM industrial partners actively engage in the educational pipeline, drawing potential employees and participating in their training through internships and other partnerships. These STEM companies realize a return on investment in the form of reduced hiring costs (recruitment) and talent development. According to STEMConnector, ${ }^{7}$ 90\% of STEM employers favor increased collaboration between industry and higher education and believe these collaborations will close the existing gap between the required skillset that is taught in the classroom and the specific skills needed to enter the STEM workforce. More importantly, STEM employers are seeking employees with discipline-specific competencies couched in teamwork, leadership, critical thinking, and problem solving. Through industrial and academic collaborations, STEM employers are able to disseminate information regarding requisite skill sets to future STEM employees.

\section{$\underline{\text { Undergraduate Research }}$}

The benefits of undergraduate research to STEM students are well documented. Students who participate in research gain hands-on experience and have more applied learning opportunities. ${ }^{8}$ Participation in undergraduate research is also linked to academic success, retention, and persistence. ${ }^{9-11}$ The characteristics of two-year college STEM students are often considered barriers to participation in undergraduate research. The few undergraduate research experiences that are available to two-year STEM students generally target those transferring to the 4- year institution during the following semester (at the junior level). The offering of undergraduate research experiences for non-transferring freshmen and sophomores at a two-year college during the following semester is a relatively new practice and thus limited. 
STEM industrial and academic partnerships in this program were carried out through STEM industry tours and undergraduate research experiences. STEM industry tours provided students with a first-hand glimpse of what is taking place in today's STEM industries, assisted them in making connections between their didactic training and real world applications, and exposed them to people working in a STEM field. Over a period of four years, STEP participants had the opportunity to tour several STEM industries in the metropolitan area.

The 3+8 undergraduate research component of STEP provided participants with an 11-week research experience. The 3-week session introduced students to research through partnering with a faculty member at the 2-year institution; this was followed by an 8-week research experience guided by research faculty members at 4-year institutions. In both components, students worked 20-25 hours per week. Students participating in the 3+8 program gained experience in collecting data, monitoring their progress, solving problems and troubleshooting, thinking and acting like experts in research practice, and preparing scientific communications. ${ }^{4}$

\section{Data Collection}

During their tenure in the program, participants were asked to complete a number of surveys and interviews to determine their reactions to and perceived outcomes of the various student support activities. Surveys probed psychosocial constructs related to student persistence and success:

1. STEM Engagement - Student engagement can be examined in terms of behavioral engagement (demonstration of interest), emotional engagement (positive reactions), and cognitive engagement (student investment in learning). Example: "I enjoy my STEM coursework."12

2. Institutional Commitment - Previous research has indicated that institutional commitment is a strong indicator of student persistence. Example: "I am committed to completing my program of study at this institution." 13,14

3. STEM Identity and Belonging - A sense of belonging and identifying with STEM contributes to student pursuit of STEM careers. Example: "I can see myself in a STEM career." 15

4. Awareness of Resources - In order for students to fully benefit from the program, they must be aware of the academic and career resources available to them; items were included to identify any issues with student awareness of available resources. Example: "I am aware of the academic resources available to me at this institution."

5. Encouragement - Studies attempting to get at influences that lead students to major in STEM have elucidated encouragement as a major factor in this decision; feeling encouraged can be a predictor of whether or not students are likely to major in a STEM discipline. Example: "I feel encouraged to get a STEM degree."16

6. Intent to Persist - Student intention to persist is highly indicative of actual persistence. Intent to persist can be examined in a temporal manner, looking at short-term, degree attainment, and long-term commitment. Example: "I intend to take more courses in STEM." 17 
Each of these constructs was measured using multiple representative items, and response options were given using a Likert scale of 1=Strongly Disagree to 5=Strongly Agree. Student surveys were administered annually using retrospective pre-post-methodology, in which students completed both time points in one sitting by looking back on their experience and remembering how they felt for the "pre" as well as how they feel currently for the "post". In this way, response shift bias, which causes students to inflate their estimation of their capabilities and positive emotions prior to experience, is eliminated. ${ }^{18}$ Students were also asked to participate in an alumni survey that gathered information about their academic and career trajectories up to 2 years after leaving the program.

In addition to student surveys, annual focus group interviews with 6-10 participants were conducted. During these interviews, students shared their thoughts about how the industrial and academic partnerships and other components of the STEP program affected them. Focus groups sessions were recorded and transcribed and coded iteratively for emergent themes.

\section{$\underline{\text { Results }}$}

Figure 1, below, indicates that students $(n=36)$ showed significant growth in all measured areas. In particular, students gained a sense of identity and belongingness to the scientific community and engagement in their chosen academic and career path. These sentiments were further explained in our numerous qualitative studies. In addition, students' institutional commitment was increased through participating in the program; not surprisingly, this factor is an indicator of persistence. Furthermore, students in the program felt that they became more aware of the many academic resources available to them. As they elaborated in interviews, these resources were sometimes seen by the students as critical to their success; without them, several students indicated that they would not have "made it" through to graduation and/or transfer. 
Figure 1. Changes in student attitudes as a result of participating in the program, Spring 2015

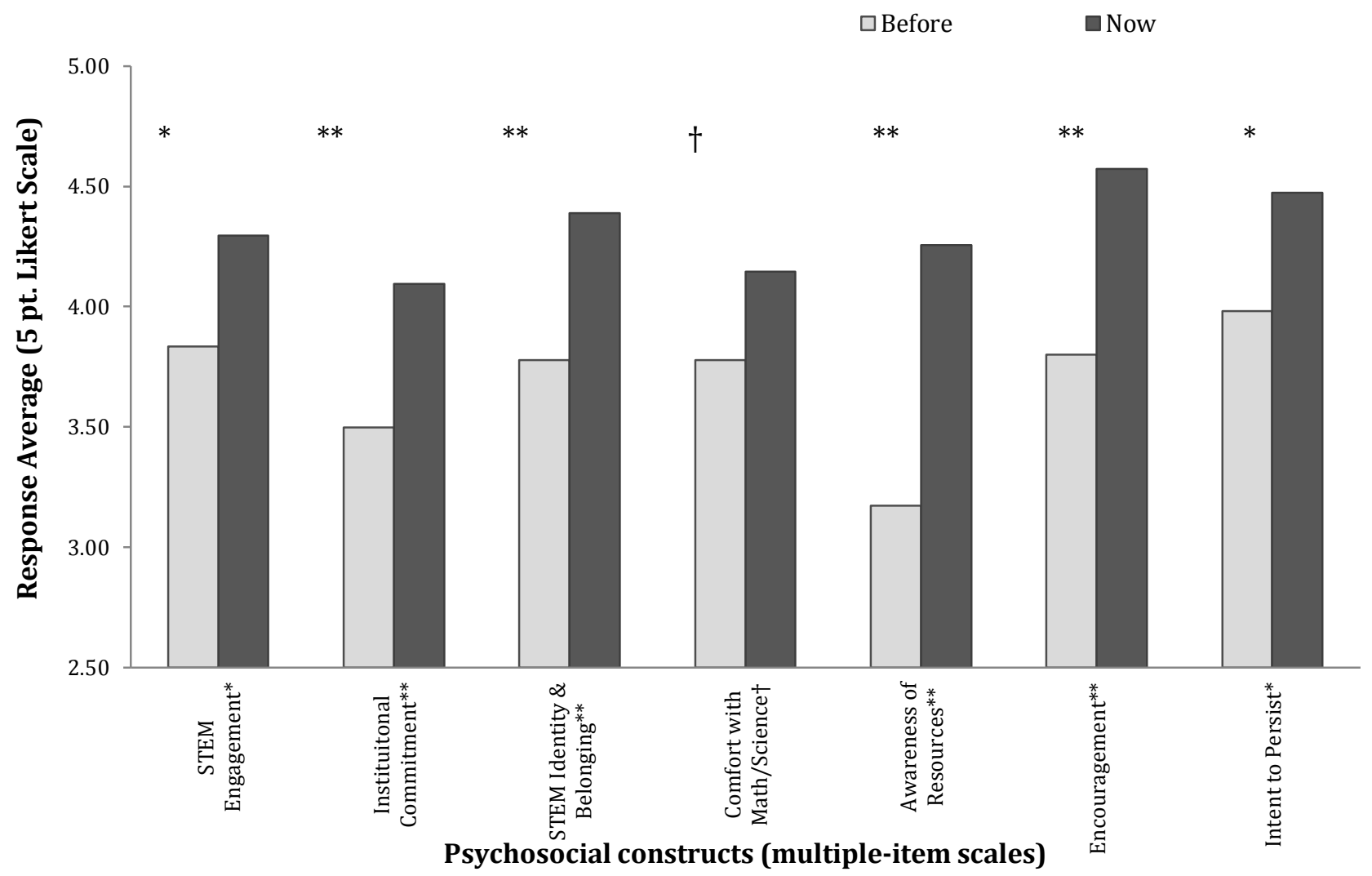

Response averages for students "before" the program and "now;" Item response options were 1=Strongly Disagree to $5=$ Strongly Agree. Levels of significance are indicated using: ${ }^{* *} \mathrm{p}<0.001,{ }^{*} \mathrm{p}<0.01,+\mathrm{p}<0.05$.

Alumni students who responded to an online survey $(\mathrm{n}=36)$ indicated that STEP was instrumental in increasing their interest in STEM, increasing their confidence that they belong in STEM, and helping them to make a commitment to a STEM career. Additionally, more than $90 \%$ of respondents felt that their participation in the program helped them to think of themselves as scientists or engineers. Other than personal advising and mentoring, students listed the programmatic research opportunities and industry visits as the top reasons for the growth.

Data gathered through surveys and focus group interviews helped us to understand why the program had these impacts and resulted in improved graduation and transfer rates for these STEM students. In particular, students participating in research and having the opportunity to explore the real-world applications of their discipline solidified their academic and career plans. The quotes below demonstrate that students were able to see themselves as scientists or engineers, and felt that they had a better understanding of where they were headed:

The Program allowed me to actually see what the science industry is like. I did biology research and organic chemistry research... through the summer bridge program. These opportunities allowed me to learn what kind of environment I 
prefer in the field. Without them, I'd have probably wasted a lot of money and time trying to go back and pursue another sector of science....

Through industry visits..., I was able to connect with the kind of industry I would like to work in... [They] helped me to define my career goals and develop a plan to obtain them.

[The program] has not only impacted my career plans but has also laid a solid foundation to my career goals. [The] provision of industrial tours, workshops, research opportunities, conferences and symposium has been instrumental. These avenues and opportunities have increased my awareness in STEM fields and has allowed me to narrow down my career choices. It has also offered me experiences, such as research, that contribute greatly to my [career goals].

Upon being in the STEP Program doing summer research, having that experience and working with people who do undergraduate and graduate research and know what it takes to do graduate/undergraduate research, and have them look at me and give me the seal of approval and tell me, "Hey, you belong here. You're doing great. Look at your lab grades," everything is telling me, "Hey, you can take this path. You can take this track, because it is for you."

Graduation and Transfer rates among STEP Participants

Only 13\% of the first-time, full-time freshmen STEM students who entered GPC in fall 2012 had either transferred and/or graduated by fall 2014. In comparison, $21 \%$ of program participants have transferred and/or graduated. Thus, students who participate in STEP are more likely to graduate and/or transfer than their peers in STEM. Student outcomes by academic year are shown in Table 2. Of the 120 participants throughout 4 years of the program, $21 \%$ have earned an associate's degree and/or transferred to 4-year colleges/universities to date, and others are on track to do so within the next two semesters.

Table 2. Student Outcomes (FY 2011- FY 2014 participants)

\begin{tabular}{lllll}
\hline \hline & Year 1: & Year 2: & Year 3: & Year 4: \\
& 2011-2012 & 2012-2013 & 2013-2014 & 2014-2015 \\
\hline Total Participants & 23 & 89 & 117 & 120 \\
Graduation/Transfer' & $5(21.7 \%)$ & $9(10 \%)$ & $22(18 \%)$ & $25(21 \%)$ \\
\hline
\end{tabular}

${ }^{1}$ Graduation and/or Transfer is defined as the number of program participants earning an Associate degree and then transferring to a 4 year institution or the number of program participants transferring to a 4 year institution without earning the Associate degree.

In comparing the institution's graduation/transfer rate with the STEM program graduation/transfer rate, students participating in the program have a higher rate of graduation/transfer than non-participants (Table 3). 
Table 3. Institution enrollment, graduation, and transfer rates for STEM students entering 2011-2012.

\begin{tabular}{lll}
\hline & Institution & STEP \\
\hline $\begin{array}{l}\text { Total Participants } \\
\text { (Enrollment) }\end{array}$ & 4402 & 117 \\
$\begin{array}{l}\text { Graduation/Transfer } \\
\text { Rate }\end{array}$ & $696(16 \%)$ & $22(18 \%)$ \\
\hline
\end{tabular}

The Institutional enrollment, graduation, and transfer rates for STEM and non-STEM students entering 2012-2013 are not available. However, based upon the trend of increasing graduation and/or transfer rate each year, presented in Table 2, we expect the percentage of graduates/transfers for program participants to be greater than that of non-program participants. It is important to note that this rate will only increase as these non-traditional students have more time to complete their academic program requirements.

Conclusion

The success of this STEP program is demonstrated by the combined graduation (with an associate's degree) and/or transfer rates. Surveys and focus group interviews helped us to identify that the academic and industrial partnerships which allowed students to conduct research and explore real-world applications of their disciplines were critical to improving persistence. In particular, students were better able to see themselves as professionals in their chosen fields because they were exposed to the realities of those industries and research settings.

Acknowledgment

This material is based upon work supported in part by the NSF Award \# 1067896.

\section{$\underline{\text { References }}$}

1. Marcus, J. (2013) New Figures Suggest Community College Grad Rates Higher than Thought. The Hechinger Report: Innovation \& Equality in Education. http://hechingerreport.org/content/new-figures-suggest-communitycollege-grad-rates-higher-than-thought_12824/)

2. Kraemer, J. (2013) Statistic of the Month: Comparing Community College Completion Rates. Center on International Education Benchmarking: Learning from the World's High Performing Education Systems. http://www.ncee.org/2013/05/statistic-of-the-month-comparing-community-college-completion-rates/)

3. Olson, S. and D.G. Riordan. (2012) Engage to excel: Producing one million additional college graduates with degrees in science, technology, engineering, and mathematics. Report to the President. Executive Office of the President, President’s Council of Advisors on Science and Technology: Washington, DC, USA.

4. Leggett-Robinson, P., Mooring, S. and Villa, B. (2015) A 3+8 Model of Undergraduate Research for Community College STEM Majors. The Journal of College Science Teaching, Vol. 44, No. 4, March/April, 2015. 
5. National Research Council. (2012). Community colleges in the evolving STEM education landscape: Summary of a summit. Washington, DC: National Academies Press.

6. Cornelis, T. (2012) Partnerships for Progress: Tying Industry to Community Colleges, STEM CONNECTOR, https://stemconnector.wordpress.com/2012/02/17/partnerships-for-progress-tying-industry-to-community-colleges/).

7. STEMConnector ${ }^{\circledR}$ Advancing a Jobs-Driven Economy: Higher Education and Business Partnerships Lead the Way, www.stemconnector.org/shec/highlights

8. Laursen, S., Seymour, E., Hunter, A. B., Thiry, H., \& Melton, G. (2010). Undergraduate research in the sciences: Engaging students in real science. San Francisco, CA: Jossey-Bass.

9. Finley, A., \& McNair, T. (2013). Assessing underserved students' engagement in high-impact practices. Washington, DC: Association of American Colleges and Universities.

10. Jones, M. T., Barlow, A. E., \& Villarejo, M. (2010). Importance of undergraduate research for minority persistence and achievement in biology. The Journal of Higher Education, 81 (1), 82-115.

11. O’Donnell, K.; Botelho, J.; Brown, J; Gonzalez, G. and Head, W. (2015) Undergraduate Research and Its Impact on Student Success for Underrepresented Students. NEW DIRECTIONS FOR HIGHER EDUCATION, no. 169, Spring 2015@2015 Wiley Periodicals, Inc. Published online in Wiley Online Library (wileyonlinelibrary.com); DOI: 10.1002/he.20120).

12. Fredricks, J. A., Blumenfeld, P. C., Friedel, J., and Paris, A. (2005). School engagement. In K. A. Moore and L. Lippman (Eds.), Conceptualizing and measuring indicators of positive development: what do children need to flourish? New York: Kluwer Academic/Plenum Press.Howard, G.S. (1980). Response-shift bias: a problem in evaluating interventions with Pre/Post self-reports. Evaluation Review, 4, 93-106.

13. Strauss, L. and Volkwein, J. (2004). Predictors of student commitment at two-year and four-year institutions. Journal of Higher Education, 75(2): 203-227.

14. Davidson, W., H. Beck, and Milligan, M. (2009). The college persistence questionnaire: development and validation of an instrument that predicts students attrition. Journal of College Student Development, 50(4): 373-390.

15. Margolis, J. http://www.exploringcs.org/about/mission

16. Leonowich-Graham, P. and Condly, S. (2010). Encouragement May be the Missing Link in the Pursuit of CS / IT Majors. Fall 2010 Mid-Atlantic ASEE Conference. October 15-16, 2010. Villanova University.

17. Tocker, Y. (2010). Non-ability correlates of the science/math trait complex: searching for personality characteristics and revising vocational interests. Doctoral Dissertation: Georgia Institute of Technology. Atlanta.

18. Pratt, C., McGuigan, W. \& Katzev, A. (2000). Measuring program outcomes: Using retrospective pretest methodology. American Journal of Evaluation,13. Strauss, L. and Volkwein, J. (2004). Predictors of student commitment at two-year and four-year institutions. Journal of Higher Education, 75(2): 203-227. 